Journal of the Egyptian Society of Parasitology, Vol.43, No.2, August 2013

J. Egypt. Soc. Parasitol., 43(2), 2013: 303 - 314

\title{
ENTERIC PROTOZOAN PARASITES IN STRAY CATS IN KUWAIT WITH SPECIAL REFERENCES TO TOXOPLASMOSIS AND RISK FACTORS AFFECTING ITS OCCURRENCE
}

\section{By}

NADRA-ELWGOUD M.I. ABDOU ${ }^{1,2}$, MAHA K. AL-BATEL ${ }^{1}$, OSAMA M.E. EL-AZAZY ${ }^{1}$, ATTIA M. SAMI ${ }^{1,3}$ AND QAIS A.H. MAJEED ${ }^{4}$

Veterinary Laboratories, Public Authority of Agriculture Affairs and Fish Resources, Kuwait ${ }^{1}$; Department of Medicine and Infectious Diseases, Faculty of Veterinary Medicine, Cairo University ${ }^{2}$; Department of Virology, Faculty of Veterinary Medicine, Cairo University, Egypt ${ }^{3}$ and Department of Science, College of

Basic Education, The Public Authority for Applied Education, Kuwait ${ }^{4}$.

Correspondence: Nadra-Elwgoud M.I. Abdou, P.O. Box 21422, Safat-13075 Kuwait. email: nadrahmed@hotmail.com

\section{Abstract}

In Kuwait, stray cats were surveyed for enteric protozoan infection using fecal examination and their sera were tested for Toxoplasma gondii IgG using indirect hemagglutination test (IHAT) as well as for feline immunodeficiency virus (FIV) antibodies and feline leukaemia virus (FeLV) antibodies using ELISA. Out of 240 fecal samples examined $22(9.2 \%)$ were found to be infected with oocysts of four species of coccidian protozoa. Isopspora felis was the most predominant enteric protozoan parasite (7.1\%), followed by $T$. gondii (2.1\%), I. rivolta (1.6), Sarcocystis was only found in one case ( $0.4 \%)$. Juvenile cats $\geq 6$ months old) had higher infection rate with oocyst of enteric protozoa than older cats ( $\mathrm{p}$-value $0.001)$.

Sero-survey of 240 stray cats revealed that $19.6 \%$ were positive to $T$. gondii IgG. Toxoplasma sero-positivity was observed in higher number of adults compared to young cats suggests that with age the risk of exposure to $T$. gondii increases. While concurrent retroviral infections were not found to be associated with increased risk for developing $T$. gondii antibodies.

Keywords: T. gondii, I. felis, FIV, FeLV, Stray cats, Kuwait.

\section{Introduction}

Stray cats are a huge part of the growing pet over-population problem everywhere. The pet cat population is estimated to be over 79 million in 2011 (Stützer and Hartmann, 2012). Although the number of cats was not estimated in Kuwait, it is common to see cats roaming in streets and they could be a potential source of environmental contamination that can lead to spread of infection to susceptible animals and in some cases humans.

Moreover, stray cats maintain a permanent infection pressure upon domestic cats that have access to the outdoors (Spada et al, 2012). 
Of the zoonotic agents transmitted by cats, $T$. gondii is the most relevant feline parasite. Although transmission of this enteric coccidian parasite can occur following the ingestion of the undercooked meat, $T$. gondii oocysts pass into the environment from the infected cats and act as significant source of infection for humans and other mammals. Cats are the main source of $T$. gondii oocysts in urban environments and information on the prevalence of exposure in cats is useful for assessing the environmental contamination by the protozoan (Dubey, 2010).

In Kuwait two studies detected the antibodies to Toxoplasma in the human population and the pregnant women (Behbehani and Alkarmi, 1980; Iqbal and Khalid, 2007).

It has been suggested that immunosuppression, resulting from lymphoid neoplasia, corticosteroid therapy, the infection with feline immunodeficiency virus (FIV) or feline leukemia virus (FeLV), might play a role in increase prevalence of enteric coccidian parasite infections (Dorny et al, 2002; Lee et al, 2002; Akhtardanesh et al, 2010).

The aim of this study was to gain the actual data of the zoonotic intestinal protozoal infections in stray cats in Kuwait. The study also examined the correlations between these infections and age, gender, season, and locality of collection where cats lived in, as well as correlations between seropositivity to FIV, FeLV and T. gondii IgG.

\section{Materials and Methods}

In a cross-sectional study, between June 2011 and May 2012, a total of 240 stray cats were trapped randomly from different areas of Kuwait State. This study was part of project designed to address many objectives including record of parasitic, viral, bacterial diseases and pathological lesions, with the permission from appropriate authorities from the Kuwaiti Public Authority of Agriculture and Fisheries, Kuwait Foundation for the Advancement of Sciences and approved by its animal ethics committee. Special traps were distributed at night in different localities of Kuwait to catch random samples of stray cats from each locality.

In the morning, the cats were transferred to the laboratory for investigations. Descriptive data of cats including age and gender were recorded. Based on dental development, maturation of genital structure and body size, the samples were divided into adult (1.5-6 $\mathrm{kg}$ ) and juvenile ( $\geq 6$ months old with $<1.4 \mathrm{~kg}$ ) age groups.

In General, the climate in Kuwait is characterized by its hot and dry season (April-November) and cold wet season (December-March). In this study, the Kuwait is divided into: Locality 1 which are inhabited by Kuwaiti and expatriates where the districts of this area are of high standard of services, low population density and without accumulation of garbage. While the Locality 2 where are many labors and workers concentrated with the highest population density and low services. 
The cats were carefully transferred to a squeezing box, and then injected with Rompun 2\% intramuscular (1.5ml/ $10 \mathrm{~kg})$. Blood samples were then collected from the heart of each cat and placed in tubes without anticoagulant for separation of serum which was stored at $-20^{\circ} \mathrm{C}$ until examined for Toxoplasma antibodies and viral infection.

The cats were [then] killed using 1-4 $\mathrm{ml}$ of T61 intracranial (according to the cat's age) and they were necropsied. Fecal samples were collected from the rectum during post-mortem examination

Direct fecal wet mount smears were examined microscopically to identify the trophozoites, as well as using concentration flotation technique for detection of oocysts or cysts of enteric protozoa. Flotation method was applied by using zinc sulphate and saturated salt solution (specific gravity 1.2) after Dryden et al. (2005). Identification of Protozoa species was based on oocyst morphology after Soulsby (1982). The McMaster slide was used to estimate the number of oocysts per gram of feces.

Determination of anti-Toxoplasma gondii specific IgG: T. gondii antibodies were detected by Indirect Hemagglutination test (IHAT) (Fumouze Diagnostics, France). Procedures given by the manufacturer's instructions were followed carefully. The samples were classified positive at titres $\geq 1 / 80$.

Virology Examination: Indirect immunoenzymatic assay (ELISA) Kit (Ingenasa, Spain) was used to test the presence of Feline Immunodeficiency virus
(FIV) antibodies and the Double antibody sandwich immunoenzymatic assay (ELISA Kit, Ingenasa, Spain) for Feline Leukaemia virus (FeLV) P27 antigen detection in the serum samples of stray cats.

Statistical analysis: Prevalence and confidence intervals (C.I) were calculated for each protozoan parasite. All the statistical calculations were performed with Statistix8 Analytical Software (version 8). The prevalence data were compared by Fisher's exact test and $\chi^{2}$ analysis was used to test for the associations between positivity for the different parasites and independent variables (gender; age; season; locality) also the relation between viral infection (FIV, FeLV) and T. gondii seropositivity. Results were considered significant at $P<0.05$.

\section{Results}

Four species of intestinal coccidian parasites were reported from 22 fecal samples of 240 stray cats. I. felis was the most prevalent, while $T$. gondii was the most abundant (Tab. 1). Young cats had significantly higher infection rate than adults $(P$-value 0.001$)$ and also higher infection rate was detected during dry season ( $P$-value 0.003$)$ while gender and locality of collection had no significant association with the prevalence of infection (Tab. 2).

The overall prevalence of $T$. gondii IgG antibodies was 19.6\% (47/240). The relationship between $T$. gondii positivity with age, gender, locality and FIV and FeLV status were presented (Tab. 3). There was a significant correlation between $T$. gondii seropositivity 
and adult age group by $\chi^{2}$ Test $(0.0002)$ and confirmed by logistic regression [odds ratio (OR) 5.34, 95\% confidence interval (CI) 2.02-14.10, $P$ $=0.003]$. While the association between $T$. gondii seropositivity and locality 1 was significant by $\chi^{2}$ Test $(0.02)$ but not with logistic regression analysis [OR 2.15, 95\% CI $=1.11-4.15, P=$ $0.17]$.

The overall FIV seropositivity was 52/218 cats $(23.9 \%)$. FIV distribution by age, gender, locality, season, and FeLV and $T$. gondii status is presented (Tab. 4). The factors significantly associated with the FIV seropositivity status included age (0.007), gender $(0.0008)$ by $\chi^{2}$ Test. Logistic regression analysis confirmed significant associations between FIV seropositivity and adulthood [odds ratio (OR) 2.86, 95\% confidence interval (CI) $1.27-6.48, P$ $=0.011]$ and male gender (OR 3.09, 95\% CI $1.59-6.29, P=0.002)$.

The overall FeLV sero-prevalence was $6 / 218$ cats $(2.8 \%)$. The FeLV distribution by age, gender, locality, season, and co-infection with FIV and $T$. gondii are presented (Tab. 5). No correlations were detected between FeLV status and gender, age, origin, district and season.

The study of co-infection with FeLV, FIV and $T$. gondii revealed that out of 218 samples tested for FeLV, FIV and T. gondii, one $(0.5 \%)$ was positive for FeLV, FIV and $T$. gondii, thirteen $(6.0 \%)$ were positive for FIV and $T$. gondii, and two $(0.9 \%)$ were positive for FeLV and T. gondii. Three of 218 samples $(1.4 \%)$ were positive for both FIV and FeLV.

\section{Discussion}

The stray cat populations play an important role in the transmission of several pathogenic agents, due to their contact with both domestic cats and humans. The importance of controlling the size of these populations and the most appropriate methods to achieve this purpose is a controversial issue of concern for municipalities and animal protection associations. Amongst the zoonotic agents transmitted by cats, $T$. gondii is one of the most important feline enteric protozoan parasites (Robertson and Thompson, 2002; Lappin, 2004). Stray cats are especially very important indicators of the environmental contamination with $T$. gondii as they shed environmentally resistant oocysts in their feces, and they are gradually increasing in number (Duarte et al, 2010). Although, there are numerous studies on the seroprevalence of $T$. gondii and other intestinal parasites of cats in many countries, this is the first study done in Kuwait.

In the present study, examination of the fecal samples of stray cats indicated that the overall protozoal infection rate was $9.2 \%$, this prevalence rate was less than that obtained by Al-Khushali (2007) in Baghdad, Iraq (35.7\%), by Schuster et al. (2009) in Dubai, UAE $(18.8 \%)$, by Arabali and Hooshyar (2009) in Kashan, Middle Iran (25.6\%) while Borji et al. (2011) in Mashad, North Iran (31.9\%), and by Khalafalla (2011) in the Nile Delta northern region, Egypt (12.4\%). These 
variations in prevalence perhaps may be due to, when only one fecal sample is collected, prepatent infections in cats as well as intermittent shedding of parasite stages may lead to the underestimation of the prevalence of parasitic infections (Sherding, 1983). Similarly, a low level of infection may go undetected when using traditional microscopy methods (McGlade et al, 2003). It is possible that protozoa may not have been detected or were under-diagnosed in earlier studies where the positive cases exceed than one third of examined fecal samples because the diagnostic techniques used were not sensitive enough to detect low levels of Protozoa. In a veterinary practice, the importance of PCR must be considered in terms of the practicality and cost effectiveness of using such a technique for routine diagnosis.

Isospora felis was the most predominant enteric protozoan parasite $(7.1 \%)$ found in stray cats in Kuwait followed by $T$. gondii (2.1\%), I. rivolta (1.6), Sarcocystis was only found in one case $(0.4 \%)$. These results agree with Al-Khushali (2007), Schuster et al. (2009), Arabali and Hooshyar (2009), Borji et al. (2011) who found that the most predominant enteric protozoa infections were I. felis but in the higher prevalence than the present results. In contrary, Khalafalla (2011) reported that prevalence of $T$. gondii oocyst in Egypt was 9\% and higher than prevalence of Isospora spp. (2\%).

In Gulf Area, many authors did not find $T$. gondii oocyst in examined cats' feces (Al-Khushali, 2007; Arabali and Hooshyar, 2009, Borji et al, 2011).
While in USA and Europe, Toxoplasma oocysts have been detected in $1 \%$ and $0.2 \%$ respectively in examined cats (Dubey and Beattie, 1988; Schares et al, 2008)

In the present study, gender of cats had no effect on the prevalence rate of coccidian parasites, but the age of the cats were found to be an important risk factor associated with their infection; consistently with these results Schuster et al. (2009) and Borji et al. (2011) found that the prevalence of Isospora spp. were higher in juvenile cats and gender had no role in infection rate.

Unexpectedly, the percentage of the protozoa-infected cases was increased during the dry season (p-value 0.003). Oocysts of Isospora spp. and T. gondii are excreted unsporulated, their sporulation and infectivity is affected by temperatures to which they are exposed and it is stopped above $45^{\circ} \mathrm{C}$ (Bowman et al, 2002). In this study, it seems that the prevalence of infection with coccidian was linked to the age and breeding season rather than environmental conditions through the year. It was noted that the highest number of 3 months old cats, the most susceptible age to infection with the coccidian protozoa particularly $T$. gondii (Davis and Dubey, 1995; Bowman et al, 2002) were trapped in dry season as the breeding season of cats in Kuwait is almost through wet/cold sea-son nearly the same breeding season of cats in Qatar (Abu-Madi et al, 2007). Subsequently, kittens prevail in the next dry/hot season; in cat colonies, this vulnerable kittens acquire infection from their dames and other cats. 
Toxoplasma sero-positivity $19.6 \%$ (47/240) of examined stray cats were positive. This result is much lower than that obtained by many authors. AlKhushali (2007) in Iraq who reported $72.2 \%$ respectively. While in stray cats in Europe, the lowest sero-prevalence of $24.2 \%$ found in Lisbon (Duarte et al, 2010), 30.5\% in Italy (Spada et al, 2012) and the highest sero-prevalence (70.2\%) found in Bel-gium by Dorny et al. (2002), as well as in stray cats (Rifaat et al, 1981) and pet ones (AlKappany et al, 2010) with isolation of viable parasite in Egypt. Al-Kappany et al. (2011) reported a high prevalence of $T$. gondii, Bartonella spp., and FIV infections in cats from Cairo. In USA, sero-positivity to $T$. gondii was $31.6 \%$ of sick domestic cats in a large feline population (Vollaire et al, 2005).

T. gondii oocyst were detected only in young cats, particularly those less than three months old and in higher intensity than other coccidian protozoa, while $T$. gondii sero-positivity was statistically significant with adult age group. The epidemiological studies on toxoplasmosis showed that cats in wild become infected soon after they are weaned by eating tissues of infected animals, and excrete large numbers (millions) of oocysts for a short period of time (2 weeks) after primaryinfection (Dubey, 1994). Mainly, these cats stop shedding oocysts in the rest of their lives, however on re-infection because of developing immunity, cats shed fewer oocysts or none at all and for a shorter time (Markell et al, 1999).

Toxoplasma sero-positivite was noted in higher number of adults compared to young cats suggests that with age the risk of exposure to $T$. gondii increases. The difference in sero-prevalence data found with respect to age coincides with other studies where higher prevalence is cited in the adult group than in the juvenile one (Smith et al, 1992; Miro et al, 2004). Despite of the seroprevalence rate in the juvenile was noticeably smaller $10.6 \%$. It was found that no antibodies to toxoplasma were detected in the sera of young cats shedding oocysts. Dubey and Beattie (1988) stated that cats may not develop antibodies during oocyst shedding period. In the same time, antibodies may not be detectable by IHAT in $T$. gondii infection during acute stage (Dubey, 1996).

As seropositive cats have likely already shed $T$. gondii oocysts, and these oocysts can remain viable in the environment for many months, serological surveys of anti- $T$. gondii antibodies in these animals could be helpful in identifying the proportion of cats that have a role in environmental contamination with fecal oocysts (Dubey and Lappin, 2006). The high prevalence of toxoplasmosis exposure in a large stray cat population may seriously contaminate the urban environment. The accidental ingestion of oocysts by contact with soil was found to be among the main factors associated with the infection of pregnant women in Europe, with between $6 \%$ and $17 \%$ of infections in different cities attributed to soil contact (Cook et al, 2000). In Kuwait, of 246 people selected at random, $95.5 \%$ gave a positive reaction to the IHAT for antibodies to T. gondii (Behbahani and 
Al-Karmi, 1980), while Iqbal and Khalid (2007) screened 119 early pregnant women serologically and $53.1 \%$ were positive for $T$. gondii IgG.

Although previous studies have recognised an association between the infections with the FIV and $T$ gondii exposure (Dorny et al, 2002; Akhtardanesh et al, 2010), no statistical association was observed in this study between $T$. gondii IgG positive cats and sero-positivity to both FIV and FeLV infection. This result was in agreement with Witt et al. (1989) and Spada et al. (2012) who reported that concurrent retroviral infections were not found to be associated with the increased risk for developing $T$. gondii antibodies.

In the present study, the overall prevalence of FIV infection in the cats ${ }^{6}$ population was $23.9 \%$. Adult age and male gender were significant predictors of FIV sero-positivity. The prevalence of FIV infection among adult males was compatible with the well knowledge that fighting and biting behaviour of stray cats in colonies is the primary mode of transmission of this infection. The FIV is effectively transmitted via bite wounds and higher cat densities would lead to more intercat aggression and fighting. Adult male cats were predisposed to FIV infection as transmission of FIV is mainly through bite wounds (Yamamoto et al, 1988). The worldwide data on FIV prevalence showed a great variation within and between countries. This variability could be caused by a number of factors, including the differences in population densities, the level of neutering, age, gender ratios and interaction between cat colonies. The overall prevalence of FIV in the present study was higher than other studies conducted in Europe on stray cat colonies; these estimates were 7\% of 490 cats in Italy (D'Amore et al,1997), 6.6\% of 196 free roaming cats in Finland (Sukura et al., 1992) and $11.3 \%$ of 346 urban stray cats in Belgium (Dorny et al, 2002). The present result was also higher than the $5.2 \%$ of 533 stray cats in north Florida (Luria et al, 2004) and $2.4 \%$ of 585 stray and feral cats in Maryland, USA (Witt et al, 1989).

In contrast to FIV infection, in which prevalence varies significantly, the FeLV infection rate of free-roaming cats is similar throughout the world, ranging from $1 \%$ to $8 \%$, and the present results support these data. In this study, the overall prevalence of FeLV was 2.8\%. In Europe, prevalence of FeLV in stray cats ranged from $1 \%$ of 196 free roaming cats in Finland to $7.1 \%$ of 198 stray cats in Lisbon (Sukura et al, 1992; Duarte et al, 2010).

In the USA, FeLV seropositivity was detected in $4.3 \%$ of 1876 free roaming cats from North Carolina and Florida (Lee et al, 2002). The lack of association between risk factors and FeLV infection in this survey could be related to the small number of cats that were FeLV-positive.

\section{Conclusion}

The outcome results of toxoplasmosis sero-prevalence rates suggested that exposure to $T$. gondii in stray cats 
is common and these cats may play an important role in the environmental contamination with the oocysts.

Informing the public about the risk of infection through contact with soil and reducing the populations of stray cats by spaying may represent measures to reduce the risk of human infection. The concurrent retroviral infections were not found to be associated with the increased risk for developing $T$. gondii antibodies.

\section{Acknowledgements}

The authors are grateful to Kuwait Foundation for Advancement of Science (KFAS) for the financial support and to the Public Authority of Agriculture and Fishers Resources (PAAF) for encouragement.

\section{References}

Abu-Madi, MA, Al-Ahbabi, DA, AlMashhadani, MM, Al-Ibrahim, R, Pal, $P$, et al, 2007: Patterns of parasitic infections in faecal samples from stray cat populations in Qatar. J. Helminthol. 81, 3:281-6.

Akhtardanesh, B, Ziaali, N, Sharifi, H, Rezaei, S, 2010: Feline immunodeficiency virus, feline leukemia virus and Toxoplasma gondii in stray and house-hold cats in Kerman-Iran: seroprevalence and correlation with clinical and laboratory findings. Res. Vet. Sci. 89, 2:306-10.

Al-Kappany, YM, Rajendran, C, Ferreira, LR, Kwok, OC, Abu-Elwafa, SA, et al, 2010: High prevalence of toxoplasmosis in cats from Egypt: isolation of viable Toxoplasma gondii, tissue distribution, and isolate designation. J. Parasitol. 96, 6:1115-8.

Al-Kappany, YM, Lappin, M, Kwok, O, Abu-Elwafa, SA, Hilali, M, et al, 2011: Seroprevalence of T.gondii \& concurrent Bartonella sp., feline immunodeficiency virus, feline leukemia virus and D.immitis infections in Egyptian cats. J. Parasitol. 97, 2:256-8.

Al-Khushali, M, 2007: Prevalence of zoonotic parasites in stray cats in Baghdad. The Iraqi Postgrad. Med. J. 6, 2: 152-6.

Arabali, M. Hooshyar, H, 2009: Gastrointestinal parasites of stray cats in Kashan, Iran. Trop. Biomed., 26, 1:1622

Behbehhani, K, Al-Karmi, T, 1980: Epidemiology to toxoplasmosis in $\mathrm{Ku}-$ wait. I. Detection of antibodies to $\mathrm{To}-$ xoplasma gondii and percentage distribution among the inhabitants. Trans. R. Soc. Trop. Med. Hyg. 74, 2:209-12.

Borji, H, Razmi, G, Ahmadi, A, Karami, H, Yaghfoori, S, et al, 2011: A survey on the endoparasites and ectoparasites of stray cats from Mashhad (Iran) and association with risk factors. J. Parasit. Dis. 35, 2:202-6

Bowman, DD, Hendrix, CM, Lindsay, DS, et al, 2002: Feline Clinical Parasitology. Blackwell Science Co., Iowa State University Press, USA.

Cook, AJ, Gilbert, RE, Buffolano, $\mathrm{W}$, Zufferey, J, Petersen, E, et al, 2000: Sources of Toxoplasma infection in pregnant woman: European multicentre case-control study. Br. Med. J. 321:142-7.

D'Amore, E, Falcone, E, Busani, L, Tollis, M, 1997: A serological survey 
of feline immunodeficiency virus and Toxoplasma gondii in stray cats. Vet. Res. Commun. 21, 5:355-9.

Davis, SW, Dubey, JP, 1995: Mediation of immunity to Toxoplasma gondii oocyst shedding in cats. J. Parasitol. 81, 6:882-6.

Dorny, P, Speybroeck, N, Verstraete, S, Baeke, M, De Becker, A, et al, 2002: Serological survey of Toxoplasma gondii, feline immunodeficiency virus and feline leukaemia virus in urban stray cats in Belgium. Vet. Rec. 151, 21:626-9.

Dryden, MW, Payne, PA, Ridley, R K, Smith, V, 2005: Comparison of the common fecal flotation techniques for the recovery of parasite eggs and oocysts. Vet. Ther. 6, 1:15-28.

Duarte, A, Castro, I, Pereira da Fonseca, IM, Almeida, V, Madeira de Carvalho, LM, et al, 2010: Survey of infectious and parasitic diseases in stray cats at the Lisbon Metropolitan Area, Portugal. J. Feline Med. Surg. 12, 6:441-6.

Dubey, JP, 1994: Toxoplasmosis. J. Am. Vet. Med. Assoc. 205, 11:1593-8.

Dubey, JP, 1996: Infectivity and pathogenicity of Toxoplasma gondii oocysts for cats. J. Parasitol. 82, 6:95761.

Dubey, JP, 2010: Toxoplasmosis of Animals and Humans. $2^{\text {nd }}$ ed. CRC Press Inc, Boca Raton, New York.

Dubey, JP, Beattie, CP, 1988: Toxoplasmosis of Animals and Man. CRC Press Inc., Boca Raton, Florida.

Dubey, JP, Lappin, R, 2006: Toxoplasmosis and neosporidiosis. In: Greene C.E. (ed). Infectious Diseases of the Dog and Cat. St Louis, MO: Saunders Elsevier.

Iqbal, J, Khalid, N, 2007: Detection of acute Toxoplasma gondii infection in early pregnancy by IgG avidity and PCR analysis. J. Med. Microbiol. 56, 11:1495-9.

Khalafalla, RE, 2011: survey study on gastrointestinal parasites of stray cats in northern region of Nile Delta, Egypt. PLoS ONE 6, 7:1-4.

Lappin, M.R. (2004): Feline zoonotic diseases. In: Proc. the $29^{\text {th }}$ World Congr. the WSAVA, October 6-9, Rhodes, Greece.

Lee, IT, Levy, JK, Gorman, SP, Crawford, PC, Slater, MR, 2002: Prevalence of feline leukaemia virus infection and serum antibodies against feline immunodeficiency virus in unowned free-roaming cats. J. Am. Vet. Med. Assoc. 220, 5: 620-2.

Luria, BJ, Levy, JK, Lappin, MR, Breitschwerdt, EB, Legendre, AM, et al, 2004: Prevalence of infectious diseases in fecal cats in Northern Florida. J. Feline Med. Surg. 6, 5:287-96.

Markell, EK, John, D, Krotoski, W, 1999: Markell \&Voges' Medical Parasitology, $8^{\text {th }}$ ed., WB. Saunders Co.

McGlade, TR, Robertson, ID, Elliot, AD, Read, C, Thompson, RC, 2003: Gastrointestinal parasites of domestic cats in Perth, Western Australia. Vet. Parasitol. 117, 4:251-62.

Miro, G, Montoya, A, Jimenez, S, Frisuelos, C, Mateo, M, Fuentes, I, 2004: Prevalence of antibodies to Toxoplasma gondii and intestinal parasites in stray, Farm, and household cats in Spain. Vet. Parasitol. 126, 3:249-55. 
Rifaat, MA, Morsy, TA, Sadek, MS, Mahmoud, AM, 1981: The antibodies against some parasites in stray cats in Cairo. J. Egypt. Soc. Parasitol. 11, 2: 517-24

Robertson, ID, Thompson, RC, 2002: Enteric parasitic zoonoses of domesticated dogs and cats. Microbes Infect. 4, 8:867-73.

Schares, G, Vrhovec, MG, Pantchev, N, Herrmann, DC, Conraths, FJ, 2008: Occurrence of Toxoplasma gondii and Hammondia hammondi oocysts in the feces of cats from Germany and other European countries. Vet. Parasitol.152, 1/2:34-45

Schuster, RK, Thomas, K, Siva-kumar, S, O'Donovan, D, 2009: The parasite fauna of stray domestic cats $(\mathrm{Fe}-$ lis catus) in Dubai, United Arab Emirates. Parasitol. Res. 105, 1:125-34.

Sherding, RG, 1983: Diseases of the small bowel. In: Ettinger, SJ. (Ed.), Text-book of Veterinary Internal Medicine: Diseases of the Dog and Cat, vol. 2. Saunders, Philadelphia.

Smith, KE. Zimmerman, JJ, Patton, S, Beran, GW, Hill HT, 1992: Epidemiology of toxoplasmosis on Iowa swine farms with an emphasis on the roles of free-living mammals. Vet. Parasitol. 42, 3/4:199-211.

Soulsby, EJL, 1982: Helminths, Arthropoda, and Protozoa of Domesticated Animals. $7^{\text {th }}$ ed. London: Baillier, Tindal and Cassel.

Table 1: Prevalence, mean intensity and protozoa (oocyst/g feces) in stray cats.

\begin{tabular}{|l|l|l|l|}
\hline & $+\mathrm{ve}(\%)$ & Intensity & Range \\
\hline All Protozoal infection & $22(9.2)$ & 6573 & $200-93600$ \\
\hline I. felis & $17(7.1)$ & 2576 & $200-19400$ \\
\hline I. rivolta & $4(1.6)$ & 350 & $200-400$ \\
\hline Sarcocyst & $1(0.4)$ & 200 & 200 \\
\hline T. gondii & $5(2.1)$ & 19840 & $200-93600$ \\
\hline
\end{tabular}

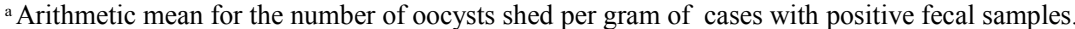

Spada, E, Proverbio, D, Pepa, A, Perego, $\mathrm{R}$, Baggiani, $\mathrm{L}$, et al, 2012: Seroprevalence of feline immunodeficiency virus, feline leukaemia virus and Toxoplasma gondii in stray cat colonies in northern Italy and correlation with clinical and laboratory data. J. Feline Med. Surg. 14, 6:369-77.

Stützer, B, Hartmann, K, 2012: Chronic bartonellosis in cats: what are the potential implications? J. Feline Med. Surg. 14, 9:612-21.

Sukura, A, Salminen, T, Lindberg, L A, 1992: A survey of FIV antibodies and FeLV antigens in free-roaming cats in the capital area of Finland. Acta Vet. Scand. 33, 1:9-14.

Vollaire, MR, Radecki, SV, Lappin, MR, 2005: Seroprevalence of Toxoplasma gondii antibodies in clinically ill cats in the United States. Am. J. Vet. Res. 66, 5: 874-7.

Witt, CJ, Moench, TR, Gittelsohn, A M, Bishop, BD, Childs, JE, 1989: Epidemiologic observations on feline immunodeficiency virus and Toxoplasma gondii coinfection in cats in Baltimore, Md. J. Am. Vet. Med. Assoc. 194, 2:229-33.

Yamamoto, JK, Sparger, E, Ho, EW, Andersen, PR, O'Connor, TP, et al, 1988: Pathogenesis of experimentally induced feline immunodeficiency virus infection in cats. Am. J. Vet. Res. 49, 8:1246-58. 
Table 2: Prevalence and 95\% confidence intervals (C.I.) of enteric protozoal infections in stray cats (240) stratified by age, gender, seasons and locality with p-value* of Fisher's exact test for comparing prevalences.

\begin{tabular}{|c|c|c|c|c|c|c|c|c|c|c|c|c|c|c|c|c|c|}
\hline & \multicolumn{4}{|c|}{ All oocysts } & \multicolumn{4}{|c|}{ I. felis } & \multicolumn{4}{|c|}{ I. rivolata } & \multicolumn{4}{|c|}{ T. gondii } \\
\hline & & 离 & 䓵 & 㺃 & 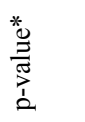 & 㐫 & 3 & 预 & 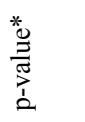 & ऐं & 3 & $\stackrel{\sqrt[0]{.00}}{\exists}$ & 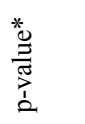 & 己ें & 3 & 总 & 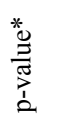 \\
\hline \multirow{2}{*}{ 芉 } & $\begin{array}{l}\text { Male } \\
(106)\end{array}$ & 12.3 & 6.7 & 20.1 & \multirow{2}{*}{0.177} & 9.4 & 4.6 & 16.7 & \multirow{2}{*}{0.218} & 2.8 & 0.6 & 8.1 & \multirow{2}{*}{0.21} & 2.8 & 0.6 & 8.1 & \multirow{2}{*}{0.66} \\
\hline & $\begin{array}{l}\text { Female } \\
(134)\end{array}$ & 6.7 & 3.1 & 12.4 & & 5.2 & 2.1 & 10.5 & & 0.7 & 0.01 & 4.1 & & 1.5 & 0.2 & 5.1 & \\
\hline \multirow[b]{2}{*}{$\underset{8}{\infty}$} & $\begin{array}{l}\text { Adult } \\
(160)\end{array}$ & 3.8 & 1.3 & 7.9 & \multirow[b]{2}{*}{0.001} & 2.5 & 0.7 & 6.2 & \multirow[b]{2}{*}{0.000} & 0 & 0 & 2.3 & \multirow[b]{2}{*}{0.01} & 0.6 & 0.01 & 3.4 & \multirow[b]{2}{*}{0.04} \\
\hline & $\begin{array}{l}\text { Young } \\
(80)\end{array}$ & 20 & 11.8 & 30.4 & & 16.2 & 8.9 & 26.2 & & 5.0 & 1.4 & 12.3 & & 5.0 & 1.4 & 12.3 & \\
\hline \multirow{2}{*}{ 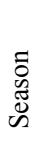 } & $\begin{array}{l}\text { Wet } \\
(129)\end{array}$ & 3.9 & 1.2 & 8.8 & \multirow[b]{2}{*}{0.003} & 3.1 & 0.9 & 7.7 & \multirow[b]{2}{*}{0.011} & 0.8 & 0.01 & 4.3 & \multirow[b]{2}{*}{0.34} & 0 & 0 & 2.8 & \multirow[b]{2}{*}{0.02} \\
\hline & $\begin{array}{l}\text { Dry } \\
(111)\end{array}$ & 15.3 & 9.2 & 23.4 & & 11.7 & 6.3 & 19.2 & & 2.7 & 0.6 & 7.7 & & 4.5 & 1.5 & 10.2 & \\
\hline \multirow{2}{*}{ 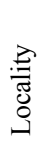 } & $1(117)$ & 8.5 & 4.2 & 15.1 & \multirow{2}{*}{0.825} & 6.8 & 2.9 & 13.0 & \multirow{2}{*}{1.000} & 1.7 & 0.2 & 6.0 & \multirow{2}{*}{1.000} & 2.6 & 0.5 & 7.3 & \multirow{2}{*}{0.67} \\
\hline & $2(123)$ & 9.8 & 5.1 & 16.4 & & 7.3 & 3.4 & 13.4 & & 1.6 & 0.2 & 5.8 & & 1.6 & 0.2 & 5.8 & \\
\hline
\end{tabular}

$P$-values in bold are statistically significant $(P<0.05)$ 
Table 3: Relationship between $T$. gondii-seropositive test results in stray cat in Kuwait (47/240 cats) and risk variables using Chi square $\left(\chi^{2}\right)$ Test

\begin{tabular}{|c|c|c|c|c|c|}
\hline Variables & Category & Positive $T$. gondii (\%) & P-value of $\chi^{2}$ & Odds Ratio & $95 \% \mathrm{CI}$ \\
\hline \multirow[t]{2}{*}{ Age } & Juvenile & $5(10.6)$ & \multirow{2}{*}{$\begin{array}{c}\mathbf{0 . 0 0 0 2} \\
(\mathbf{0 . 0 0 3})^{*}\end{array}$} & 0.19 & $0.07-0.50$ \\
\hline & Adult & $42(89.4)$ & & 5.34 & $2.02-14.10$ \\
\hline \multirow[t]{2}{*}{ Gender } & Male & $18(38.3)$ & \multirow{2}{*}{0.36} & 0.74 & $0.39-1.42$ \\
\hline & Female & $29(61.7)$ & & 1.35 & $0.70-2.60$ \\
\hline \multirow[t]{2}{*}{ Season } & Wet & $26(55.3)$ & \multirow{2}{*}{0.81} & 1.08 & $0.57-2.05$ \\
\hline & Dry & $21(44.7)$ & & 0.90 & $0.49-1.75$ \\
\hline \multirow[t]{2}{*}{ Locality } & 1 & 27 (57.4) & \multirow{2}{*}{$\begin{array}{c}\mathbf{0 . 0 2} \\
(0.17)^{*}\end{array}$} & 2.15 & $1.11-4.15$ \\
\hline & 2 & $20(42.6)$ & & 0.47 & $0.24-0.89$ \\
\hline \multirow[t]{2}{*}{ FIV test results } & Positive & $27(67.5)$ & \multirow{2}{*}{0.16} & 1.72 & $0.81-3.63$ \\
\hline & Negative & $13(32.5)$ & & 0.58 & $0.28-1.23$ \\
\hline \multirow{2}{*}{$\begin{array}{l}\text { FeLV test } \\
\text { results }\end{array}$} & Positive & $2(5.12)$ & \multirow{2}{*}{0.32} & 0.42 & $0.07-2.39$ \\
\hline & Negative & $37(94.8)$ & & 2.09 & $0.32-13.55$ \\
\hline
\end{tabular}

$P$-values in boldstatistically significant $(P<0.05) . *$ Data from logistic regression analysis

Table 4. Relationship between FIV-seropositive test results in stray cat in Kuwait (52/218 cats) and risk variables using Chi square $\left(\chi^{2}\right)$ Test

\begin{tabular}{|c|c|c|c|c|c|}
\hline Variables & Category & Positive FIV (\%) & P-value of $\chi^{2}$ & Odds Ratio & $95 \% \mathrm{CI}$ \\
\hline \multirow[t]{2}{*}{ Age } & Juvenile & $11(21.2)$ & \multirow{2}{*}{$0.007(0.011)^{*}$} & 0.38 & $0.18-0.79$ \\
\hline & Adult & $41(78.8)$ & & 2.86 & $1.27-6.48$ \\
\hline \multirow[t]{2}{*}{ Gender } & Male & $36(30.7)$ & \multirow{2}{*}{$\begin{array}{c}\text { 0.0008 } \\
(\mathbf{0 . 0 0 2})^{*}\end{array}$} & 3.09 & $1.59-6.29$ \\
\hline & Female & $16(14.3)$ & & 0.32 & $0.17-0.63$ \\
\hline \multirow[t]{2}{*}{ Season } & Wet & $26(50.0)$ & \multirow{2}{*}{0.45} & 0.78 & $0.42-1.47$ \\
\hline & Dry & $26(50.0)$ & & 1.27 & $0.68-2.38$ \\
\hline \multirow[t]{2}{*}{ Locality } & 1 & $29(55.8)$ & \multirow{2}{*}{0.21} & 1.50 & $0.80-2.79$ \\
\hline & 2 & $23(44.2)$ & & 0.67 & $0.36-1.25$ \\
\hline \multirow[t]{2}{*}{ FeLV test results } & Positive & $3(5.8)$ & \multirow{2}{*}{0.14} & 3.20 & $0.62-16.38$ \\
\hline & Negative & $3(5.8)$ & & 0.31 & $0.06-1.60$ \\
\hline \multirow[t]{2}{*}{ T. gondii test results } & Positive & $13(32.5)$ & \multirow{2}{*}{0.16} & 1.72 & $0.81-3.63$ \\
\hline & Negative & $39(21.9)$ & & 0.58 & $0.28-1.23$ \\
\hline
\end{tabular}

$P$-values in bold statistically significant $(P<0.05)$, ${ }^{*}$ Data from logistic regression analysis

Table 5. Relationship between FeLV-seropositive test results in stray cat in Kuwait (6/218 cats) and risk variables using Chi square $\left(\chi^{2}\right)$ Test

\begin{tabular}{|c|c|c|c|c|c|}
\hline Variables & Category & Positive FeLV (\%) & P-value of $\chi^{2}$ & Odds Ratio & $95 \% \mathrm{CI}$ \\
\hline \multirow{2}{*}{ Age } & Juvenile & $1(16.7)$ & \multirow{2}{*}{0.39} & 0.39 & $0.05-3.44$ \\
\hline & Adult & $5(83.3)$ & & 2.5 & $0.29-22.11$ \\
\hline \multirow[t]{2}{*}{ Gender } & Male & $3(50.0)$ & \multirow{2}{*}{0.80} & 1.23 & $0.24-6.24$ \\
\hline & Female & $3(50.0)$ & & 0.81 & $0.16-4.1155$ \\
\hline \multirow[t]{2}{*}{ Season } & Wet & $4(66.7)$ & \multirow[t]{2}{*}{0.46} & 1.89 & $0.34-10.54$ \\
\hline & Dry & $2(33.3)$ & & 0.53 & $0.09-2.95$ \\
\hline \multirow[t]{2}{*}{ Locality } & 1 & $3(50.0)$ & \multirow{2}{*}{0.96} & 1.04 & $0.20-5.26$ \\
\hline & 2 & $3(50.0)$ & & 0.96 & $0.19-4.88$ \\
\hline \multirow[t]{2}{*}{ FIV test results } & Positive & $3(50.0)$ & \multirow{2}{*}{0.14} & 3.20 & $0.62-16.38$ \\
\hline & Negative & $3(50.0)$ & & 0.31 & $0.06-1.60$ \\
\hline \multirow[t]{2}{*}{ T. gondii test results } & Positive & $2(33.3)$ & \multirow{2}{*}{0.32} & 0.42 & $0.07-2.39$ \\
\hline & Negative & $4(66.7)$ & & 2.09 & $0.32-13.55$ \\
\hline
\end{tabular}

